\title{
Evaluating Techniques for Joining Piezo-Electric Elements on Test Structures for Performing Vibration-Based Measurement Methods ${ }^{\dagger}$
}

\author{
Christian Gundlach *(D), Stefan Meyer, Chris Hopmann, Klaus Dilger (D) and Sven Hartwig
}

Citation: Gundlach, C.; Meyer, S.; Hopmann, C.; Dilger, K.; Hartwig, S. Evaluating Techniques for Joining Piezo-Electric Elements on Test Structures for Performing Vibration-Based Measurement Methods. Eng. Proc. 2021, 6, 91. https://doi.org/10.3390/ I3S2021Dresden-10078

Academic Editors: Gianaurelio Cuniberti and Larysa Baraban

Published: 17 May 2021

Publisher's Note: MDPI stays neutral with regard to jurisdictional claims in published maps and institutional affiliations.

Copyright: (c) 2021 by the authors. Licensee MDPI, Basel, Switzerland. This article is an open access article distributed under the terms and conditions of the Creative Commons Attribution (CC BY) license (https:// creativecommons.org/licenses/by/ $4.0 /)$.
Institute of Joining and Welding, Technische Universität Braunschweig, 38106 Braunschweig, Germany; stefan.meyer@tu-braunschweig.de (S.M.); chris.hopmann@web.de (C.H.); k.dilger@tu-braunschweig.de (K.D.); s.hartwig@tu-braunschweig.de (S.H.)

* Correspondence: c.gundlach@tu-braunschweig.de

+ Presented at the 8th International Symposium on Sensor Science, 17-28 May 2021; Available online: https://i3s2021dresden.sciforum.net/.

\begin{abstract}
When performing vibration-based measurement techniques, e.g., for structural health monitoring, piezo-electric elements are often used as the sensor and/or actuator part due to their durability. The connection between the piezo-electric element and the test structure plays a decisive role in the quality of the results obtained in the vibration-based measurement process. In addition to stable and mode-independent vibration transmission, further requirements such as reversibility or temperature resistance can be imposed depending on the application. In many preliminary studies, bonding by means of a two-component epoxy resin was practically and simulatively validated for a large amount of use cases. Nevertheless, the limited reversibility and the preparation time of the adhesion process can limit the flexibility of the vibration-based measurement method. The aim of this work is to evaluate different joining technologies of piezo-electric elements on metal and polymer substrates, especially with respect to reversibility. Different techniques for joining piezo elements are collected, considering previous work as well as newly developed approaches within the scope of the work. In the next step, frequency spectra of simple circular blanks are obtained using an EMI setup of piezo elements joined to the blanks with the appropriate joining technique. Joining by means of a two-component epoxy is considered as the reference method. All joining techniques are evaluated, especially based on the degree of reversibility, transmission quality, effort for implementation and durability, in comparison to the reference method. Finally, recommendations regarding the proper joining technique for different experimental conditions are given based on the results.
\end{abstract}

Keywords: piezo-electric elements; non-destructive testing; joining techniques; vibration-based measurement; reversibility; plastic and metal substrates

Supplementary Materials: The poster presentation is available online at https: / / www.mdpi.com/ article/10.3390/I3S2021Dresden-10078/s1.

Institutional Review Board Statement: Not applicable.

Informed Consent Statement: Not applicable. 